\title{
Demonstrating the Efficacy of the Health Sciences and Technology Academy: Using Archival Standardized Test Scores to Analyze an OST College-Preparatory Program for Underserved Youth
}

\author{
Feon M. Smith', Sherron B. McKendall², Ann Chester², Bethany Hornbeck ${ }^{3}$, and Alan R. McKendall² \\ ${ }^{1}$ Marshall University, Huntington, WV; ${ }^{2}$ West Virginia University, Morgantown, WV; ${ }^{3}$ Health Sciences and Technology Academy, Grafton, West Virginia \\ Keywords: out-of-school-time programs, statistical analysis, standardized test, stem enrichment, at risk students \\ Publication Date: September 24, 2018 \\ DOI: https://doi.org/10.15695/jstem/v1i1.19
}

\begin{abstract}
To combat educational and health disparities, out-of-school-time (OST) STEM enrichment programs provide services to underserved youth to encourage them to pursue college and health careers. This article describes a study conducted to determine if the Health Sciences and Technology Academy (HSTA) program participants who receive year-round educational interventions to prepare them for STEM and health sciences majors performed better on the West Virginia Educational Standards Test (WESTEST2) than non-participants. This study provides descriptive and inferential statistics, specifically one-way ANOVAs with one-to-one matching based on grade level, gender, race, and GPA at the end of the 8th grade year for 336 students. Statistically significant differences were found favoring HSTA participants on the WESTEST2 math and reading/language scores.
\end{abstract}

\section{INTRODUCTION}

For decades, the U.S. has grappled with the question of how to reduce the achievement gap between students at risk and their peers. While numerous legislative actions have been implemented to prepare all students, regardless of background, for success in college and beyond, underprivileged students continue to face many barriers on the road to higher education, not the least of which is adequate preparation for and competitive performance on standardized tests (Civil Rights Act, 1964; U.S. Department of Education, 2015). In the absence of proper support, which can be provided by out-of-school-time (OST) programs, underserved students risk poor performance on these exams, which can, in turn, eliminate crucial educational opportunities during their primary and secondary schooling and sabotage their bid for entry into a college or university.

Standardized Tests and the Achievement Gap. Poverty and its associated physical, sociological, and psychological problems (Fryer and Levitt, 2004; Berliner, 2009) along with gender roles (Eccles, 1987) have long been recognized and documented as barriers to achievement for underprivileged populations. More recently, the role of stereotype threat (Spencer et al., 1999; Steele et al., 2002), also referred to as collective threat (Cohen and Garcia, 2005), has been linked to lower academic performance in underrepresented groups. Studies (Willingham and Cole, 1997; Ryan and Ryan, 2005; Fernandes et al., 2016) have demonstrated that African American students, especially African American males, tend to score lower on standardized math tests than White and Asian students (U.S. Department of Education, 2001; McFarland et al., 2017). Research has also found that African Americans significantly underperform on standardized tests, particularly in the areas of math and science (College Board, 2015; Ferreira, 2002; Finkel, 2010; Hedges and Nowell, 1999). Research on "stereotype threat" points to this phenomenon as one cause of African Americans' and other underserved groups' poor performance. These studies illuminate a social/psychological context in which individuals from stereotyped groups display impaired performance by virtue of a predisposition of conforming to or fear of reinforcing the negative stereotype of the group. (Steele, Spencer, and Aaronson, 2002; Cohen and Garcia; 2005). Thus, culturally tolerated stereotypes (e.g., African Americans are intellectually inferior to Whites, males are better at math than females) can hinder an individual's academic performance if the individual identifies with the group. Empirical studies have validated these theories (Schmader, 2002; Murphy et al., 2007; Kellow and Jones, 2008). 
To secure bright futures for African American and all underrepresented students, we must, as individuals and collectively, focus on minimizing the impact of obstacles on their academic and social achievement by providing interventions to improve their educational experiences (Whaley, 2017). One important mechanism for helping these students reach their potential is out-of-school-time (OST) programming, which provides academic and/or social enrichment outside the day-to-day classroom. With rising emphasis on STEM education in the United States, OST programs can be particularly valuable for at-risk student populations by affording extra support in the areas of math and science to successfully pursue STEM-based post-secondary degrees and enter high-value STEM-based careers after graduation (PR Newswire, 2015; Verizon, 2014; Wilson et al., 2012; Le et al., 2015; McKendall et al., 2014; Carter et al., 2009; McKendall et al., 2000).

Context for This Study. The Health Sciences and Technology Academy (HSTA) is a college preparatory program for at-risk youth in the state of West Virginia with a primary mission to provide support, stimulate academic success, and ultimately increase college enrollment for the state's at-risk youth population, which includes African American, economically challenged, first-generation-to-college, and rural students. HSTA also hopes to "home grow" productive citizens who would provide healthcare services to the medically underserved populations of West Virginia.

HSTA has carried out its mission through a program structure that emphasizes high expectations, individualized academic achievement, experiential learning, social support, and the creation of a strong STEM foundation in its students. It uses research-based after-school and summer camp curricula and an expansive social support structure to nurture underserved high school students who have the potential and desire to pursue a career in healthcare or another STEMbased profession. HSTA participants who successfully complete the program, are offered a tuition and fee waiver to West Virginia state colleges and universities, which may be used to obtain an associates or undergraduate degree of their choosing, as well as a graduate or professional degree in most health science and other STEM majors and the field of law.

\section{METHODS}

This study examines the standardized test scores of HSTA program participants compared to a comparable control group to determine if there are significant differences in test outcomes. One-way ANOVA (Analysis of Variance) and the retrospective causal-comparative or ex-post-facto research design (Fraenkel and Wallen, 2009) were used to compare the 2009-2010 mean test scores between HSTA and
non-HSTA students on the West Virginia Educational Standards Test (WESTEST 2), the state-mandated exam used during the time of this study (Time 4 Learning, 2015). This annual assessment of students in grades 3-11 determined their strengths and weaknesses relevant to academic content areas and identified performance levels on West Virginia's 21st Century Content Standards and Objectives (CSOs). This study used archived, de-identified, pre-existing data (i.e.,WESTEST 2 math and reading/language arts scores) from HSTA and non-HSTA students for the 2009-2010 academic year. Study participants in grades 9th, 10th, and 11th were matched one-to-one (HSTA vs. non-HSTA) based on demographics (i.e., race and gender), grade level, place of residency (i.e., county, school attending), and grade point averages (GPA). The demographic comparisons between HSTA and non-HSTA students did not examine the participants' age. Furthermore, it is assumed that the non-HSTA group did not advance through the academic continuum more slowly (i.e., repeated grades), since both groups were matched by the 3.0 or above grade point average at the end of their 8th grade year. The matching criteria controlled for selection bias in the program in that the non-HSTA subjects were eligible to participate in the program based on the HSTA criterion. Thus, the variables of race (e.g., African American), first generation college, financially disadvantaged, and rural were utilized when constructing the non-HSTA control population. The exclusion criterion for potential non-HSTA students was a GPA less than 3.0, and if a HSTA or non-HSTA subject had a missing math or reading/language arts score, both the sample and the matched comparison were removed from the study (Stuart and Rubin, 2007). The final sample of matched students were de-identified for analyses with the combined data sets (i.e., HSTA and non-HSTA).

The students included in this investigation attended twelve West Virginia high schools hosting 20 HSTA clubs. A cross-section of 168 HSTA students and 168 non-HSTA students was sampled, totaling 336 study participants, including 148 African American females, 82 African American males, 48 White females, 38 White males, ten Hispanic females, four Hispanic males, and six Asian females. For the purpose of this paper, only comparisons between the African American and White participants were examined. Other populations were too small. Study participants were not followed through the course of their four years in the program.

HSTA staff identified HSTA clubs in West Virginia with the highest numbers of African American students in the program following HSTA's mission to assist at-risk populations with a focus on African American youth. After identifying these clubs, recruitment letters were sent to six superintendents of the counties' individual school districts. Five superintendents agreed to participate in the study, for a participation rate of $83 \%$. Superintendents subsequently provided a signed letter of permission indicating their volun- 
tary agreement to participate. Compiled data sets (i.e., name, race/ethnicity, gender, county of residency, school attending, and GPA) of all HSTA students attending clubs in participating districts were sent to the school districts. The schools also received a cover letter detailing which data (i.e., WESTEST 2 Math and Reading/Language Arts scaled scores) to include for the HSTA students and instructions on how to select non-HSTA students for subsequent matching. School districts performed the following tasks:

(1) Recorded the West Virginia Education Information System (WVEIS) number and WESTEST 2 scores for each HSTA student in the spreadsheet next to the name.

(2) Provided notes and corrected any discrepancies in the HSTA data from the HSTA central office.

(3) Randomly selected a comparison group of non-HSTA students from the county and selected and provided the same information as was provided for the HSTA students. If a district was unclear as to how to perform the random selection, the researcher was available to provide further instruction.

(4) The data for both HSTA and non-HSTA students were placed on a compact disk and sent to HSTA's main office.

Data Analysis. The data from this study was analyzed using descriptive and inferential statistics, specifically oneway ANOVA (Analysis of Variance) utilizing the Statistical Package for Social Science. G*Power (version 3.1.9.1) was used to perform post-hoc effect size and power analyses with power $(1-b)$ set at the following parameters: the effect size for each test, sample size, standard deviation for HSTA and non-HSTA, and $\alpha=.05$ (Faul et al., 2014). There were three primary comparisons:

- Overall mean WESTEST 2 scores in reading and math for HSTA students vs. non-HSTA students

- HSTA student scores vs. non-HSTA student scores by gender (e.g., HSTA males vs. non-HSTA males)

- HSTA student scores vs. non-HSTA student scores by race and gender (e.g., HSTA African American males vs. non-HSTA African American males) Additional posthoc t-tests using the Statistics Calculator StatPac (version 4.0)

\section{RESULTS}

In nearly every comparison, HSTA students significantly outperformed the non-HSTA matched cohort. Analysis of variance showed a statistically significant difference between the cohorts for math scores, $\mathrm{F}(1,334)=13.040$, $\mathrm{p}=$ .001 , and reading/language arts scores, $\mathrm{F}(1,334)=12.993$, $\mathrm{p}=.001$ (Figure 1). These findings were significant across gender and race. HSTA male math scores, $\mathrm{F}(1,122)=5.364$, $\mathrm{p}=.022$ and HSTA female math scores, $\mathrm{F}(1,210)=7.621, \mathrm{p}$ $=.006$ were significantly higher than Non-HSTA male and female scores respectively (Figure 2). Similarly, HSTA male reading/language arts scores, $\mathrm{F}(1,122)=8.360, \mathrm{p}=.005$ and female HSTA reading/language arts scores, $\mathrm{F}(1,210)=$ $5.746, \mathrm{p}=.017$ were significantly higher than their Non-HSTA counterparts (Figure 3 ).

WESTEST 2 had five performance-level categories for each core content area (Table 1). A comparison of mean scores revealed that HSTA students' overall performance level on the WESTEST 2 was an entire level higher (Above Mastery) in both math (655.40) and reading (496.57) compared to non-HSTA students whose significantly different mean score in math was $634.06(\mathrm{p}=.001)$ and in reading was $477.95(\mathrm{p}=.001)$ (Figure 1). This indicates a lower mastery level or basic meeting of standards for the comparison group. The effect size (i.e., $\eta 2 p$ ) for the overall comparisons of standardized math (0.39) and reading (0.39) scores indicates that $39 \%$ of the total variance in both math and reading scores can be accounted for by participation in the

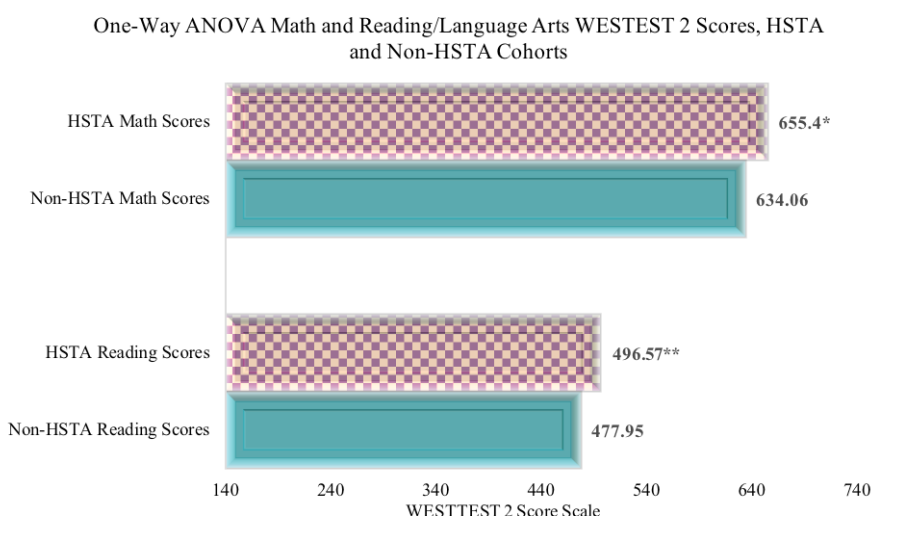

Figure 1. $* \mathrm{p}=.001, * * \mathrm{p}=.001$

Table 1. WESTEST 2 Performance Levels for Math and Reading Language/Arts Scores

\begin{tabular}{ccccc}
\hline Performance Levels & Distinguished & Above Mastery & Mastery** & Partial Mastery \\
\hline $\begin{array}{c}\text { Math Scores: } \\
\text { Reading/Language Arts } \\
\text { Scores: }\end{array}$ & $840-682$ & $681-652$ & $651-626$ & $625-597$ \\
\hline
\end{tabular}

Distinguished: Student demonstrates knowledge, comprehension, application, analysis, synthesis, and evaluation of skills, which exceed the standard; Above Mastery: Student demonstrates knowledge, comprehension, application, and analysis of skills, which exceed the standard; Mastery**: Student demonstrates knowledge, comprehension, and application of skills, which meet the standard; Partial Mastery: Student demonstrates knowledge and recall of skills toward meeting the standard; Novice: Student does not demonstrate knowledge and recall of skills needed to meet the standard. ${ }^{*}$ Mastery Level performance or higher was considered proficient in content areas (West Virginia Department of Education, 2010). 
One-Way ANOVA Math WESTEST 2 Scores, HSTA and Non-HSTA Male and Female Cohorts
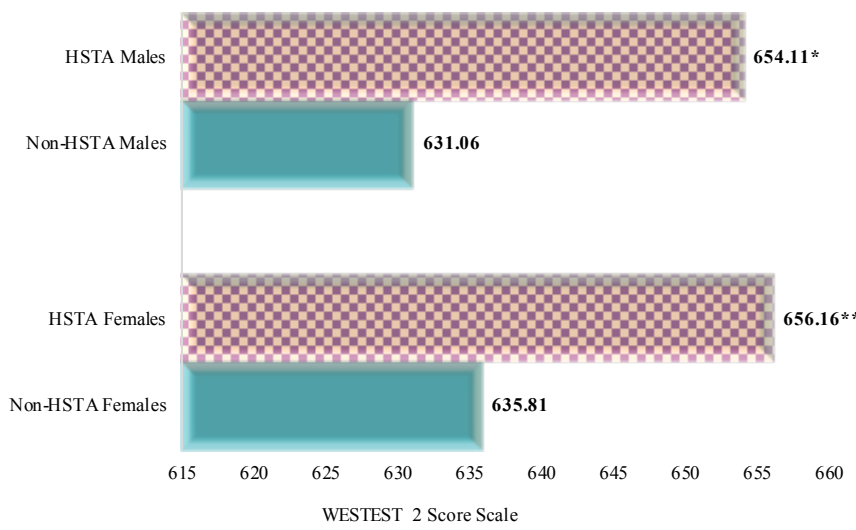

One-Way ANOVA Reading/Language Arts WESTEST 2 Scores, HSTA and NonHSTA Male and Female Cohorts

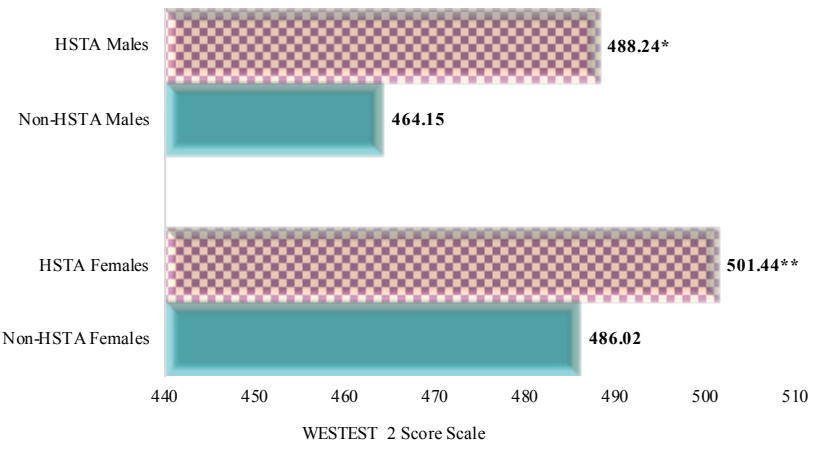

One-Way ANOVA Reading/Language Arts WESTEST 2 Scores, HSTA White and Non-HSTA White Male and Female Cohorts
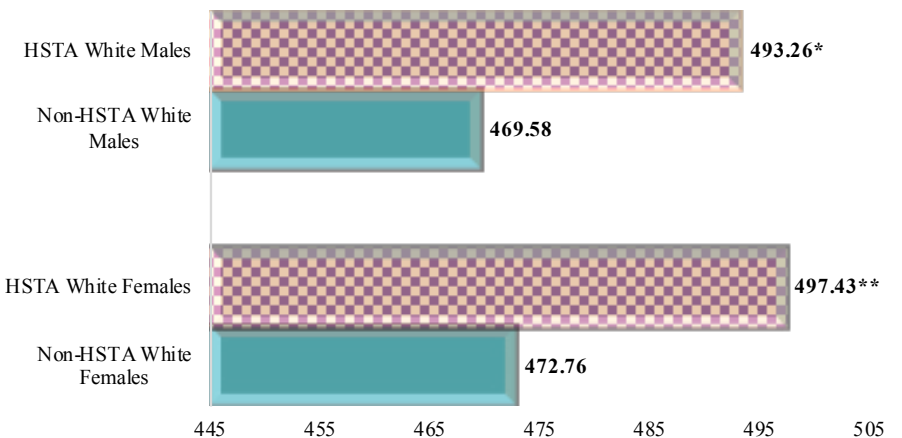

WESTEST 2 Score Scale

Top to Bottom: Figure 2. $* \mathrm{p}=.022,{ }^{*} \mathrm{p}=.006$. Figure 3. $* \mathrm{p}=$ $.005, * * p=.017$. Figure 4. $* \mathrm{p}=.028, * * \mathrm{p}=.022$.

HSTA program. Furthermore, power tests for the analyses of math $(0.975)$ and reading $(0.974)$ scores for the detection of a moderate effect indicates more than adequate power (i.e., power * .80) for the moderate effect size level of both test scores (Cohen, 1988).

Comparative analyses by gender also showed that HSTA students scored at higher levels than their non-HSTA counterparts did. HSTA females' math score was 656.16 (Above Mastery) vs. 635.81 (Mastery), with an effect size of 38\% and a power test for analysis at $87 \%$ for a moderate effect size level. In addition, the HSTA females' reading/language arts score was an entire level higher at 501.44 (Above Mastery) compared to 486.02 (Mastery) for non-HSTA females with an effect size of $33 \%$ attributed to participation in HSTA, but with a power test for analyses of only $77 \%$. Correspondingly, HSTA males' math scores were also an entire level higher (Above Mastery) than their non-HSTA counterparts, at 654.11 versus 631.06 (Mastery), with an effect size of $41 \%$. The reading/language arts scores for HSTA males were at the Mastery level range at 488.24 compared to 464.15 (Partial Mastery) for non-HSTA males, with 52\% of the total variance attributed to participation in HSTA and a power test for analyses of $89 \%$.

Comparisons by race and gender showed significant differences for reading/language arts scores favouring HSTA students. White male and White female HSTA students' reading/language arts scores compared to their non-HSTA peers showed significant differences and accounted for $74 \%$ (White males) and 74\% (White females) of the total variance due to participation in the HSTA program for both cohorts. HSTA White male students' math scores were a level above their non-HSTA counterparts with math at 666.37 (Above Mastery) and reading/language arts 493.26 (Mastery) compared to non-HSTA math at 632.95 (Mastery) and reading/language arts at 469.58 (Partial Mastery). HSTA White males outperformed their non-HSTA counterparts with significant differences shown on the reading/language arts scores, $\mathrm{F}(1,36)=5.325, \mathrm{p}=.028$ and HSTA White female reading/language arts scores, $\mathrm{F}(1,46)=5.722, \mathrm{p}=.022$ were significantly higher than Non-HSTA White male and female scores, respectively (Figure 4). HSTA White male math scores, $\mathrm{F}(1,36)=3.704, \mathrm{p}=.062$ and HSTA White female math scores, $F(1,46)=3.921, p=.055$ were not significantly different from their non-HSTA counterparts (Figure 5). Despite non-significance, HSTA White females' math scores were Above Mastery (670.05) compared to 637.24 (Mastery) for non-HSTA White females. The reading/language arts score for the White HSTA female cohort was also 497.43 (Above Mastery) vs. 472.76 (Mastery) for their non-HSTA White female counterparts.

Comparative analyses of HSTA compared to non-HSTA African American student scores revealed results favouring this cohort of HSTA participants, with math and reading/language arts scores at the Mastery Level. African American HSTA males' reading scores, $\mathrm{F}(1,80)=4.363, \mathrm{p}=.040$ ) were significantly different from their non-HSTA peers, accounting for $46 \%$ of the total variance. Furthermore, HSTA's African American males scored 483.54 (Mastery) on the reading/language arts section, which was one performance level above their non-HSTA counterparts at 459.73 (Partial Mastery). HSTA African American females' reading/language arts scores, $\mathrm{F}(1,146)=3.627, \mathrm{p}=.059)$ were not significantly different from their non-HSTA counterparts (Figure 6). 


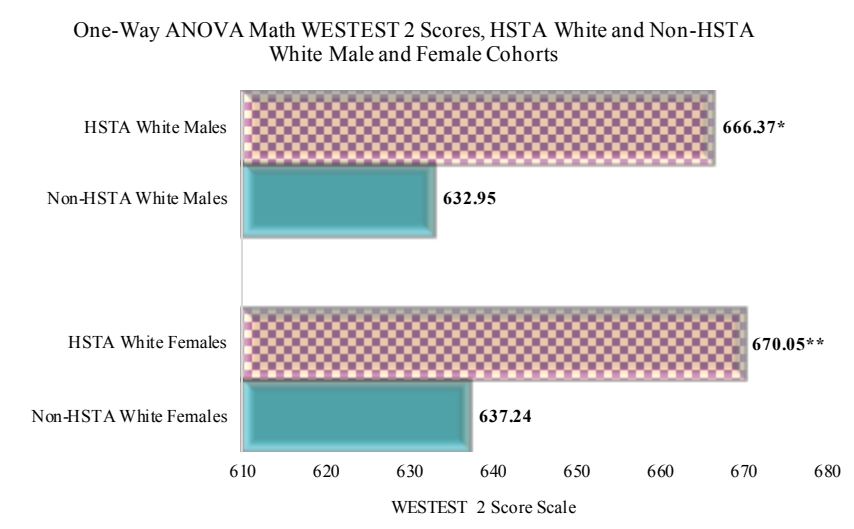

One-Way ANOVA Math WESTEST 2 Reading/Language Arts Scores, HSTA African American and Non-HSTA African American Male and Female Cohorts

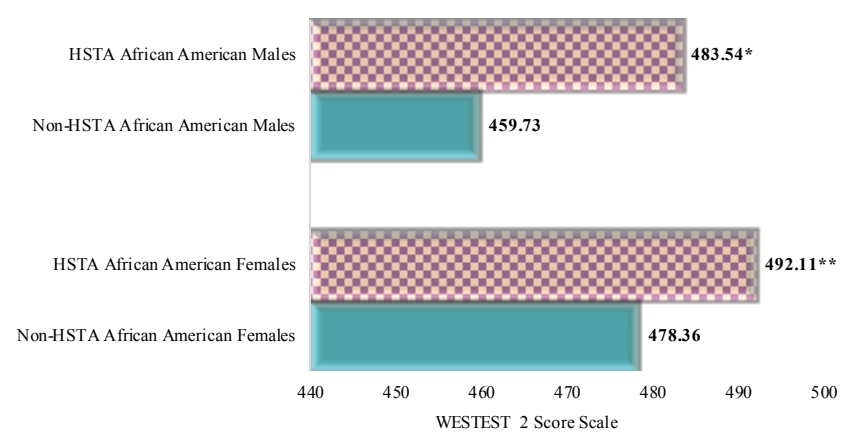

One-Way ANOVA Math WESTEST 2 Scores, HSTA African American and Non-HSTA African American Male and Female Cohorts

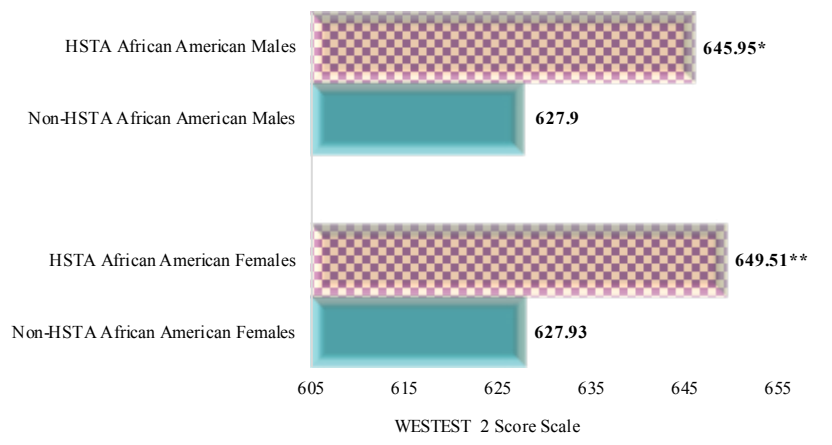

Top to Bottom. Figure 5. ${ }^{*} \mathrm{p}=$ not significant, ${ }^{* *} \mathrm{p}=$ not significant. Figure 6. $* p=.040, * * p=$ not significant. Figure 7. $* p=$ not significant, $* * p=.012$
The math scores for HSTA African American males compared to their non-HSTA counterparts were not significantly different, $\mathrm{F}(1,80)=2.137, \mathrm{p}=.148$. However, HSTA African American female students' math scores showed significant difference from their non-HSTA counterparts, $\mathrm{F}(1,146)=$ $6.54, \mathrm{p}=.012)$, accounting for $42 \%$ of the total variance due to participation in HSTA and a 0.82 power analysis attributing a moderate effect (Figure 7). African American female HSTA and non-HSTA students were on par with reaching Mastery level for both math (649.51 vs. 627.93) and reading/ language arts scores (492.11 vs. 478.36). Despite not showing Above Mastery skill levels as their White HSTA counterparts, the African American HSTA students gained at least 13.75 to at most 23.81 more points on the tests than their non-HSTA African American counterparts with matched GPAs.

While there were significant differences in the mean math and reading/language arts scores of HSTA compared to non-HSTA participants, there were no differences found when comparing within the groups by race and gender. Thus, HSTA's African American males and females did not differ in their math and reading/language arts scores from HSTA White males and females (Table 2). Comparisons of HSTA African American to White males showed no significant difference in the math scores, $\mathrm{t}(58)=1.269, \mathrm{p}=.2095$ and reading/language arts scores, $\mathrm{t}(58)=0.897, \mathrm{p}=.3735$. African American and White HSTA females also did not differ in their math scores, $\mathrm{t}(96)=1.714, \mathrm{p}=.0897$ and reading/ language arts scores, $\mathrm{t}(96)=0.577, \mathrm{p}=.5655$ as well. This was also the case for non-HSTA within-group comparisons Table 3). However, a most significant finding revealed that HSTA White females $(\mathrm{N}=21)$ and non-HSTA White males $(\mathrm{N}=19)$ showed significant differences in their math scores. HSTA White females had an Above Mastery score of 670.05 compared to 632.95 (Mastery) for non-HSTA White males $(t(38)=2.186, p=.0351)$. It is also important to note that despite non-significance on the math scores, HSTA African American females and males scored 649.51 and 645.95, respectively showing only a 16.56 and 13.00 difference in the score ranges compared to non-HSTA White males.

Table 2. One-Way ANOVA Math and Reading/Language Arts WESTEST 2 Scores, Comparison of All HSTA students

\begin{tabular}{lcccccc}
\hline Variable & Source of Variation & DF & Sum of Squares & Mean Squares & F-ratio & p-value \\
\hline Math Scores: & Between & 3 & 13222.7 & 4407.6 & 1.526 & 0.21 \\
& Within & 154 & 444832 & 2888.5 & & \\
\hline Reading Scores: & Total & 157 & 458054.7 & & & \\
& Between & 3 & 3459.2 & 1153.1 & 0.751 & 0.524 \\
& Within & 154 & 239532 & 1553.9 & & \\
\hline
\end{tabular}

Note: $F(.05,3,154)=2.61$ Given that our $F$ ratios are not equal to or smaller than the critical F-value, there is no significant difference in the mean math and reading scores for HSTA's African American and White students. 
Table 3. Post-hoc Independent groups t-test of Math and Reading/ Language Arts WESTEST 2 Scores, Non-HSTA African American Males and Females Compared to Non-HSTA White Males and Females

\begin{tabular}{lccccc}
\hline Variable & N & $X$ & df & t-value & p-value \\
\hline Math Scores & & & & & \\
\hline NHAAM & 14 & 627.9 & 58 & 0.349 & 0.729 \\
NHWM & 19 & 632.95 & & & \\
NHAAF & 74 & 627.93 & 96 & 0.751 & 0.455 \\
NHWF & 24 & 637.24 & & & \\
\hline Reading/ & & & & & \\
Language & & & & & \\
Arts Scores: & & & & & \\
\hline NHAAM & 41 & 459.73 & 58 & 0.674 & 0.503 \\
NHWM & 19 & 469.58 & & & \\
NHAAF & 74 & 478.36 & 96 & 0.544 & 0.588 \\
NHWF & 24 & 472.76 & & & \\
\hline
\end{tabular}

Note. NHAAM = Non-HSTA African American Male $;$ NHWM $=$ Non-HSTA White Male; NHAAF $=$ Non-HSTA African American Female; NHWF $=$ Non-HSTA White Female

This study is not without limitation. When constructing the control group, a formal propensity score matching was not conducted which would have included using baseline scores (test scores prior to the 9th grade). Thus, the data collected was limited to grades 9th, 10th, and 11th. Given this factor, this is considered a primary limitation since the 8th grade test scores might be considered an important predictor of the latter test scores. Furthermore, it could be argued that baseline test scores are necessary for analysis of program effect on latter test scores. Future research on HSTA and non-HSTA participants standardized test scores could address an expansion of this study to include baseline data. Nevertheless, without considering 8th grade baseline scores, it is difficult to argue that the HSTA intervention did not have an impact on the test scores of these students since both HSTA and non-HSTA participants have the same criteria of race (e.g., African American), first generation college goers, financially disadvantaged, rural and were matched one-toone on these criteria as well as grade-level, gender and GPA.

One might argue that there is a selection bias into the program which brings into question the validity of this study. We acknowledge that there is a possibility of selection bias; however, this study provides a controlled evaluation (Winkelby et al., 2014) on a matched cohort study of HSTA and non-HSTA high school participants to determine if the outcomes are program versus selection effect.

\section{DISCUSSION}

Traditionally, standardized test scores are used to measure academic success in school. This practice becomes particularly powerful as learners progress through the educational pipeline. Higher test scores are linked to positive outcomes, such as the inclination to study academically rigorous areas, including STEM fields, as well as the propensity to pursue college education. HSTA students have higher test scores both overall and by race/gender, which indicates that the academic foundation and educational interventions they receive support their heightened performance on these tests, with significant evidence showing differences between program participants compared to non-participants who have the same 8th grade GPA and are of the same race and gender. The results indicate that HSTA African American students are surpassing their non-HSTA counterparts, and although their scores are not on the same mastery level as White HSTA students, there were no significant differences in the math scores between HSTA's African American and White students. African American and female HSTA students are making significant academic strides, and for all participants, the higher WESTEST 2 scores show the promise of both greater preparedness in attending college and pursuit of post-secondary study. HSTA African American males are outperforming their counterparts in reading, despite research showing that African American males are poor readers and in defiance of the resulting stereotype threat that would otherwise impede their ability to compete in the academic arena (The National Assessment of Educational Progress, 2015).

The work of Steele et al. (2002) provides two primary organizational strategies for lessening the effects of stereotype and social identity threats: Relational and Contextual. Relational strategies are enacted via friendship, expert tutors, mentoring, ability affirmation, and success-affirming role models and mentors. HSTA offers these crucial social connections for its participants at school, in their communities, and through relationships with universities (Figure 8). HSTA students build friendships with fellow participants and interact with college-aged mentors from similar backgrounds who have successfully completed HSTA. Participants receive affirmation by recognition of their accomplishments through HSTA events and the media (e.g., newspapers). Each student is required to complete, yearly, an in-depth research project with the guidance of expert tutors and HSTA-trained teachers, an undertaking that presents challenging standards and promotes an authentic sense of success upon completion. HSTA also encourages parental/family involvement in the science symposia, where students present their research projects, and by coordinating parent meetings (McKendall et al., 2014).

According to Steele et al. (2002), contextual strategies define the setting as one in which social identity is valued, di- 


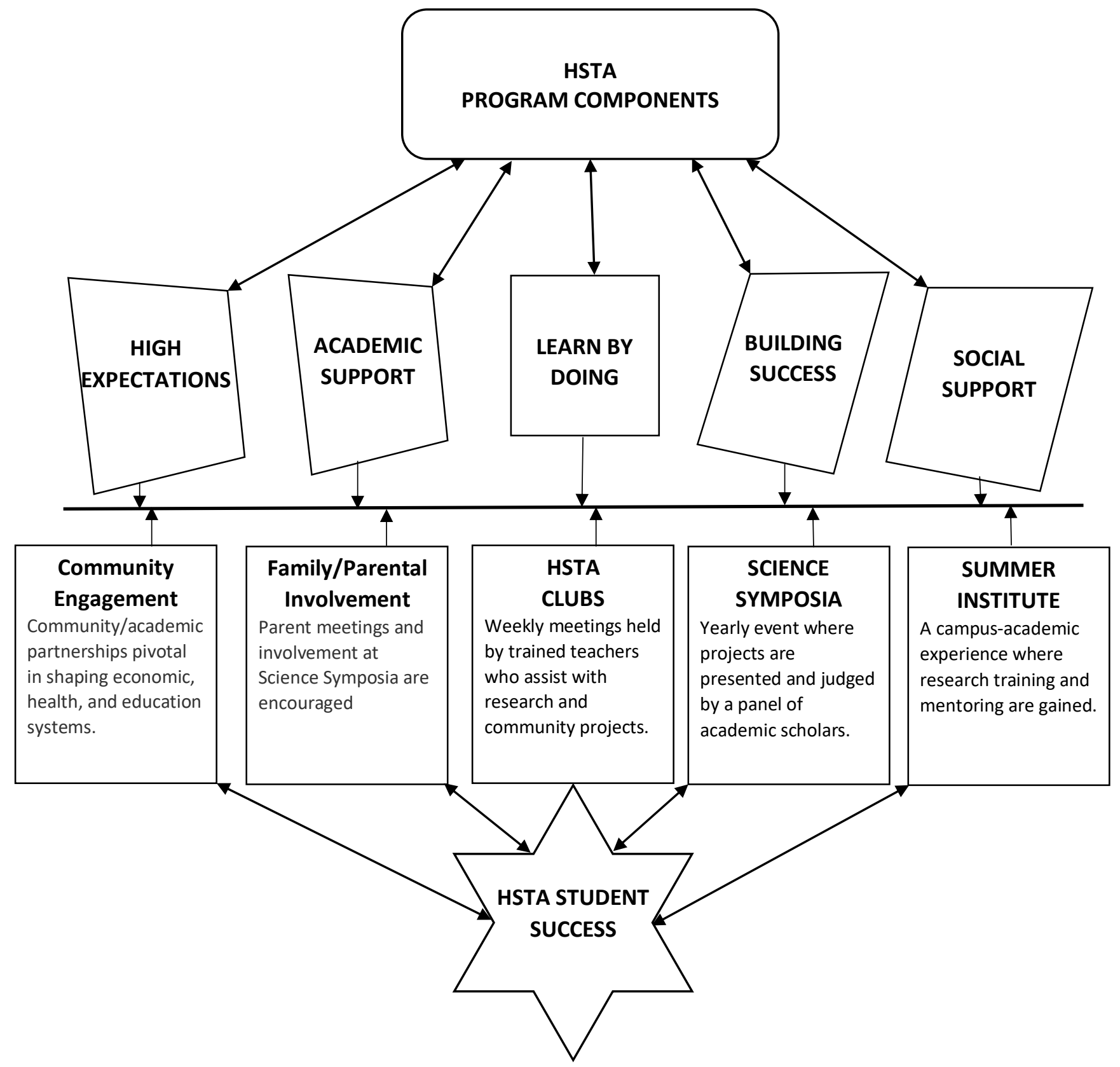

Figure 8. HSTA’s Social Support Structure

verse philosophy and minority presence are represented, and procedural justice is implemented. HSTA participation creates an atmosphere in which students regularly interact with individuals from similar backgrounds who have overcome difficult odds by gaining college entry, earning high-level degrees, and securing successful careers. As a grass-roots organization, HSTA policies and procedures are set and guided by a panel of community members in the participants' HSTA region (e.g., parents, business owners, medical practitioners, etc.), ensuring that HSTA students are governed by a group with their best interests in mind and further creating an atmosphere of procedural justice and minority trust. All students, with no exceptions, are held accountable by way of probation or possible expulsion if they do not meet program standards.

By modeling relational and contextual strategies, HSTA maintains an environment that dampens the effects of stereotype threat and social identity stigma. With this supportive structure in place, at-risk students have a greater chance for academic achievement. They receive consistent affirmation that they belong, that they can succeed, and that they have a support system that they can depend on through high school, college, and beyond.

Academic enrichment is often the focus of content for STEM outreach programs. While not doubting the importance of academic enrichment, the social support element of the HSTA model is potentially a vital means of negating the risks of stereotype and social identity threats, which intro- 
duce students to the risk of poor performance on standardized tests. For several years, HSTA has disseminated a variety of survey instruments on the various program components (i.e., Summer Institute, Community Based Program) as well as the HSTA Exit Evaluation Instrument to assess impact and effectiveness from the participants' perspective. From these instruments, HSTA has gleaned a wealth of qualitative data citing the importance of HSTA's social support structure to the participants:

... (A)n amazing program . . more people should know more about it. It has been a pleasure to be apart (sic) of this program ... It has taught me many things I feel are going to be important to me in my following career, and I just wanted to say thank you for everything. The program that you offer is a privilege... (Exit Evaluation, 2017-2018)

I will really miss my club and friends around the state. Thank you for your support for my education. Thank you for the waiver. (Exit Evaluation, 2017-2018)

HSTA was a wonderful experience and helped me tremendously when facing my fears of public speaking. It helped strengthen my college application and helped so much when paying for college as my family received little to none financial aid. (Exit Evaluation, 2017-2018)

This is one of the best decisions I have ever made. I met a lot of new friends and multiple people that can help me on my journey through college and life. (Senior Camp, 2017)

I have always wanted to go to college, but having the experience of living in a dorm for three weeks with some people I've never met but ultimately became close friends with them. I also liked the statistics class because it gave me the opportunity to put my skills to the test and really challenge myself. (Senior Camp 2017)

I had a lot of fun and learned a lot. I was around people who had the same passions as me and supportive adults who wanted to do nothing but help. (Forensics Science Camp, 2016)

School was never an option growing up, being in foster homes didn't give me any hope that one day I would turn out to be this young lady I am now. I thought that I wouldn't make (it) past the age of ten, but I did . .., I didn't turn out like a druggie I turned out to be a smart, kind, young lady. MU made me see that in me and I hope other people can climb out of their hole that people have put them in or that they dug for themselves and change their lives or the ones around them. It might be difficult at first but there's always a light at the end of the tunnel and... they can make it. I'm going to spread the word about MU to my friends and tell them how nice it really is . . I really liked my stay at Marshall University. (Fun with Science Camp, 2015)

My favorite thing about Biomed was all of the people that I had the pleasure of meeting. Everyone was interesting and exceptional and a pleasure to be around. The mentors were helpful and approachable and really helped to guide me over the week. The lesson . . was engaging and interesting and well done and sparked an interest in me that I didn't know that I had. Biomed was overall an incredible experience in my life that I will remember for years to come. (Biomedical Camp, 2014)

I met some very interesting advisers and students who taught me a lot about their field. M.M., specifically (even though he is a student and not faculty) had an impact on me. He revealed to me a career opportunity that combines two of my passions, computers and mathematics, and has inspired me to pursue a dual degree in the two subjects. Every other faculty member has inspired me with their passion and driven me to find a field that I am as interested in as they are so that I may enjoy myself as much as they do. (Biomedical Camp, 2014)

According to the National Institute on Out Of School Time (NIOST), students who participate in quality OST programs experience outcomes such as improved school attendance, higher levels of engaged learning, increased test scores and grades, and decreased levels of disciplinary problems, factors that impact the pursuit of post-secondary study (NIOST, 2009). The aforementioned outcomes are also the result of an important factor provided to OST program participants - social support (Curtis et al., 2014; McKendall et al., 2014). In light of the above anecdotal evidence, HSTA is in the midst of evaluating the impact of social support systems. HSTA is intended to interweave academic rigor and social support with the ultimate goal of providing resources to encourage participants' retention and progression through the educational pipeline and beyond.

\section{CONCLUSION}

As an OST/STEM enrichment program, HSTA offers participants essential tools to improve upon gatekeeper qualifications - namely, standardized tests. This is a breakthrough for students who historically exhibit lower standardized test scores. HSTA students engage in challenging, diverse curriculum and build relationships with each other and with academic mentors. These experiences are shown to support students in being more effective test takers (McKendall et al., 2014; Afterschool Alliance, 2015; Hodges et al., 2017). As such, the effect of HSTA is twofold: Students receive the support and educational resources essential to pursuing post-secondary study, and they go on to use this academic trajectory to attain vital careers in health sciences and other STEM areas (Table 4). The goals set in place through HSTA are upheld by creating community-academic partnerships, fostering family involvement, and implementing the core program components of the HSTA club, the Science Symposia, and the Summer Institute. Thus, HSTA 
Table 4. Health Care Professions Majors and Careers Chosen by Graduates of the West Virginia Health Sciences and Technology Academy, 1997-2017

\begin{tabular}{|c|c|c|}
\hline & All graduates & $\begin{array}{c}\text { African American } \\
\text { graduates }\end{array}$ \\
\hline $\begin{array}{l}\text { Medicine and pre-med } \\
(\mathrm{MD}, \mathrm{DO})\end{array}$ & 80 & 24 \\
\hline $\begin{array}{l}\text { Medicine, non-MD (phy- } \\
\text { sician assistant, nurse } \\
\text { practitioner, etc.) }\end{array}$ & 28 & 4 \\
\hline Dentistry & 35 & 4 \\
\hline Nursing & 239 & 56 \\
\hline Pharmacy & 43 & 12 \\
\hline $\begin{array}{l}\text { Rehabilitative care (phys- } \\
\text { ical therapy, occupational } \\
\text { therapy, sports medicine, } \\
\text { etc.) }\end{array}$ & 99 & 34 \\
\hline $\begin{array}{l}\text { Patient care, other (med- } \\
\text { ical assistant, respiratory } \\
\text { therapy, etc.) }\end{array}$ & 120 & 34 \\
\hline $\begin{array}{l}\text { Public and community } \\
\text { health }\end{array}$ & 22 & 4 \\
\hline $\begin{array}{l}\text { Health care administra- } \\
\text { tion }\end{array}$ & 19 & 11 \\
\hline Mental health care & 142 & 50 \\
\hline Radiology and related & 32 & 14 \\
\hline $\begin{array}{l}\text { Allied health care (speech } \\
\text { pathology, audiology, } \\
\text { etc.) }\end{array}$ & 34 & 13 \\
\hline $\begin{array}{l}\text { Research and pre-health } \\
\text { care professional (bio- } \\
\text { medical science, biology, } \\
\text { chemistry, etc.) }\end{array}$ & 161 & 41 \\
\hline $\begin{array}{l}\text { STEM areas (Science, } \\
\text { Technology, Mathemat- } \\
\text { ics, Engineering) }\end{array}$ & 245 & 51 \\
\hline
\end{tabular}

*Health professions degrees include associates degrees and professional degrees.

diligently seeks to create positive educational environments and outcomes while attempting to dismantle the phenomena of stereotype-threat performance (Steele et al., 2002). Essentially, these findings suggest that there is a positive correlation between program participation and higher standardized test scores, which exemplifies that HSTA, and potentially other OST STEM enrichment programs, have the potential to affect the most important indicator of acceptance into post-secondary institutions. As previously mentioned, HSTA is in the process of continually validating through longitudinal analyses the importance of a social support system to dismantling educational barriers for HSTA participants. Further analyses through evidenced-based research of other
OST STEM programs should be conducted in order to build upon the research substantiating the viability of these programs in assisting at-risk students to overcome educational barriers in pursuit of a higher standard of living.

\section{AUTHOR INFORMATION Corresponding Author}

Sherron McKendall, smckendall@hsc.wvu.edu. Health Sciences and Technology Academy, West Virginia University (WV).

ORCID iD: 0000-0003-2371-0753

\section{Author Contributions}

The manuscript was written through contributions of all authors. All authors have given approval to the final version of the manuscript.

\section{ABBREVIATIONS}

OST: out-of-school-time; HSTA: Health Sciences and Technology Academy; WESTEST2: West Virginia Educational Standards Test; ANOVA: Analysis of Variance

\section{ACKNOWLEDGEMENTS}

We thank Danielle Costello for assistance with editing this manuscript.

\section{REFERENCES}

Afterschool Alliance. (2015). Evaluations Backgrounder: A Summary of Formal Evaluations of Afterschool programs' Impact on Academics, Behavior, Safety and Family Life. Retrieved March 9, 2018 from http://afterschoolalliance. org//documents/Evaluation_Backgrounder.pdf

Berliner, D. C. (2009). Poverty and Potential: Out-of-School Factors and School Success. Boulder and Tempe: Education and the Public Interest Center \& Education Policy Research Unit. Retrieved March 8, 2018 from http://nepc. colorado.edu/publication/poverty-and-potential

Carter, F. D., Mandell, M., and Maton, K. I. (2009). The Influence of On-Campus, Academic Year Undergraduate Research on STEM Ph.D. Outcomes: Evidence From the Meyerhoff Scholarship Program. Educational Evaluation and Policy Analysis, 31(4), 441-462. doi:10.3102/0162373709348584

Civil Rights Act. (1964). Public Law 88-352. Retrieved March 9, 2018 from http://library.clerk.house.gov/referencefiles/ PPL_CivilRightsAct_1964.pdf

Cohen, G. L., and Garcia, J. (2005). "I am us": Negative Stereotypes as Collective Threats. Journal of Personality and Social Psychology, 89(4), 566-82. DOI: 10.1037/00223514.89.4.566.

College Board. (2015). 2015 College Board Program Results. Retrieved March 9, 2018 from https://www.collegeboard.org/ program-results/2014/sat 
College Board. (2014). The 2014 SAT Report on College \& Career Readiness. Retrieved March 9, 2018 from https:// research.collegeboard.org/programs/sat/data/archived/ cb-seniors-2014

Curtis, R., Matthew, S., Georgieva, Z., Smith, M., Moore, L., Chester, A., and McKendall, S., (2014). Rural student voices to improve educational attainment oriented programs. Journal of Behavioral and Social Sciences. 1, 66-73.

Eccles, J. S. (1987). Gender roles and women's achievement-related decisions. Psychology of Women Quarterly, 11(2), 135-172. doi:10.1111/j.1471-6402.1987.tb00781.x

Faul, F., Erdfelder, E., Buchner, A., and Lang, A.G. (2014). $\mathrm{G}^{*}$ Power Version 3.1.9.2 [computer software]. Uiversität Kiel, Germany. Retrieved from http://www.softpedia.com/ get/Science-CAD/G-Power.shtml

Fernandes, R., Ha, I. S., McElroy, S. W, and Myers, S. L. (2016). Black-White disparities in test scores: Distributional characteristics. The Review of Black Political Economy, 43(2), 209-232. doi:10.1007/s12114-015-9230-5

Ferreira, M. (2002). Ameliorating equity in science, mathematics, and engineering: A case study of an after-school science program. Equity and Excellence in Education, 35(1), 4349. doi:10.1080/713845242

Finkel, E. (2010). Black Children Still Left behind, District Administration. Retrieved March 9, 2018 from http://eric. ed.gov/?id=EJ908810

Fraenkel, J. R. and Wallen, N. E. (2009). How to Design and Evaluate Research in Education (7th ed). New York. McGraw-hill

Fryer, R. and Levitt, S. (2004). Understanding the Black-White test score gap in the first two years of school. The Review of Economics and Statistics, 86(2), 447-464. doi:10.3386/ w8975.

Hedges, L. V. and Nowell, A. (1999). Changes in the Black-White gap in achievement test scores: The evidence from nationally representative samples. Sociology of Education, 72, 111-135.

Hodges, J., Mcintosh, J., and Gentry, M. (2017). The effect of an out-of-school enrichment program on the academic achievement of high-potential students from low-income families. Journal of Advanced Academics, 28(3), 204-224. doi:10.1177/1932202x17715304

Kellow, J. T. and Jones, B. D. (2008). The effects of stereotypes on the achievement gap: Reexamining the academic performance of African American high school students. Journal of Black Psychology, 34(1), 94-120. doi: $10.1177 / 0095798407310537$

Le, V., Mariano, L. T., and Faxon-Mills, S. (2015). Can college outreach programs improve college readiness? The case of the college bound, St. Louis program. Research in Higher Education, 57(3), 261-287. doi:10.1007/s11162-0159385-8

McFarland, J., Hussar, B., de Brey, C., Snyder, T., Wang, X., Wilkinson-Flicker, S., Gebrekristos, S., Zhang, J., Rathbun, A., Barmer, A., Bullock Mann, F., and Hinz, S. (2017). The Condition of Education 2017 (NCES 2017144). U.S. Department of Education. Washington, DC: National Center for Education Statistics. Retrieved March 9, 2018 from https://nces.ed.gov/pubsearch/pubsinfo.asp?pubid $=2017144$
McKendall, S. B., Simoyi, P., Chester, A., and Rye, J. A. (2000). The Health Sciences and Technology Academy: Utilizing pre-college enrichment programming to minimize post-secondary education barriers for underserved youth. Academic Medicine Supplement, 75(10), S121-S123.

McKendall, S. B., Kasten, K., Hanks, S., and Chester, A. (2014). The Health Sciences and Technology Academy: An educational pipeline to address health care disparities in West Virginia. Academic Medicine : Journal of the Association of American Medical Colleges, 89(1), 37-42. http://doi. org/10.1097/ACM.0000000000000047

Murphy, M., Steele, C., and Gross, J. (2007). Signaling threat: How situational cues affect women in math, science, and engineering settings. Psychological Science, 18(10), 879885. doi:10.1111/j.1467-9280.2007.01995.x

National Institute on Out-of-School Time. (2009). Making the Case: A 2009 Fact Sheet on Children and Youth In Out-ofSchool-Time. Retrieved March 9, 2018 from https://www. niost.org/pdf/factsheet2009.pdf

PR Newswire. (2015). Four Northern California Schools to Launch Innovative New STEM Programs with Support from Verizon. Retrieved from http://www.prnewswire. com/news-releases/four-northern-california-schools-tolaunch-innovative-new-stem-programs-with-supportfrom-verizon-300024120.html

Ryan, K. E., and Ryan, A. M. (2005). Psychological processes underlying stereotype threat and standardized math test performance. Educational Psychologist, 40(1), 53-63. doi:10.1207/s15326985ep4001_4

Schmader, T. (2002). Gender identification moderates stereotype threat effects on women's math performance. Journal of Experimental Social Psychology, 38(2), 194-201. doi:10.1006/jesp.2001.1500

Spencer, S., Steele, C., and Quinn, D. (1999). Stereotype threat and women's math performance. Journal of Experimental Social Psychology, 35(1), 4-28. doi:10.1006/jesp.1998.1373

StatPac, Inc. (1997-2016). Statistics Calculator Version 4.0. https:// www.statpac.com/

Steele, C. M., Spencer, S. J., and Aronson, J. (2002). Contending with group image: The Psychology of stereotype and social identity threat. Advances in Experimental Social Psychology, 34, 379-440. doi:10.1016/s0065-2601(02)80009-0

Stuart, E. A. and Rubin, D. B. (2007). Best Practices in Quasi-Experimental Designs: Matching methods for causal inference. In J. Osborne (Ed.), Best Practices in Quantitative Social Science (pp. 155-176). Thousand Oaks, CA: Sage Publications.

The National Assessment of Educational Progress (NAEP). (2015). Mathematics Performance. Chapter 3 Elementary and Secondary Education Section: Assessments. The Condition of Education 2015. Retrieved March 9, 2018 from https://nces.ed.gov/pubs2015/2015144.pdf

Time 4 Learning. (2015). West Virginia WESTEST Test Prep. About West Virginia's Standardized Tests for 3rd-11th Grades. Retrieved March 9, 2018 from http://www.time4learning.com/testprep/index.php/west-virginia-standardized-test-prep/

U.S. Department of Education, National Center for Education Statistics. (2015). SAT mean scores of college-bound seniors, by race/ethnicity: Selected years, 1986-87 through 201213. Digest of Education Statistics, 2013 (NCES 2015011). Retrieved March 9, 2018 from https:// nces.ed.gov/ fastfacts/display.asp?id=171 
U.S. Department of Education, National Center for Education Statistics, The Condition of Education 2001, NCES 2001072, Washington, DC: U.S. Government Printing Office, 2001 .

Verizon. (2014). Verizon Champions Innovative STEM Programs at 80 U.S. Public Schools. Verizon Innovate Learning Grants to Help Underserved Schools Stimulate Students' Interest in Tech Fields. Retrieved March 9, 2018 from http://3blmedia.com/News/Verizon-Champions-Innovative-STEM-Programs-80-US-Public-Schools

Willingham, W. and Cole, N. (1997). Gender and fair assessment. Mahwah, N.J.: L. Erlbaum Associates.Winkelby, M. A., Ned, J., Ahn, D., Koehler, A., Fagliano, K., and Crump, C. (2014). A controlled evaluation of a high school biomedical pipeline program: Design and methods. Journal of Science Education and Technology, 23(1), 138-144. doi: 10.1007/s10956-013-9458-4

Whaley, A. (2017). Advances in stereotype threat research on African Americans: Continuing challenges to the validity of its role in the achievement gap. Social Psychology of Education, 1(1). doi:10.1007/s11218-017-9415-9

Wilson, Z. S., Holmes, L., deGravelles, K., Sylvain, M. R., Batiste, L., Johnson, M., McGuire, S. Y., Pang, S. S., and Warner, I. M. (2011). Hierarchical mentoring: A transformative strategy for improving diversity and retention in undergraduate STEM disciplines. Journal of Science Education and Technology, 21(1), 148-156. doi:10.1007/s10956-011-9292-5 